\title{
Special Topics in Electromagnetics
}


This page intentionally left blank 


\section{Special Topics in Electromagnetics}

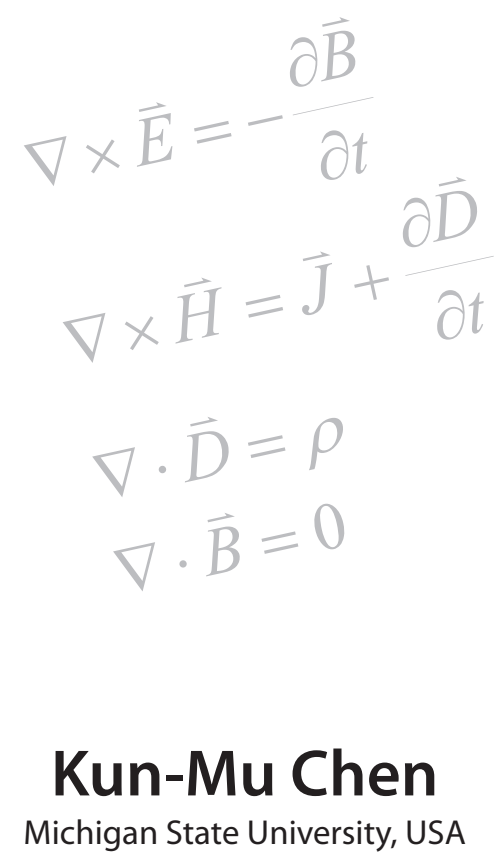

Kun-Mu Chen
Michigan State University, USA 


\section{Published by}

National Taiwan University Press

1, Sec 4, Roosevelt Road

Taipei, Taiwan

and

Distributed by

World Scientific Publishing Co. Pte. Ltd.

5 Toh Tuck Link, Singapore 596224

USA office: 27 Warren Street, Suite 401-402, Hackensack, NJ 07601

UK office: 57 Shelton Street, Covent Garden, London WC2H 9HE

\section{British Library Cataloguing-in-Publication Data}

A catalogue record for this book is available from the British Library.

\section{SPECIAL TOPICS IN ELECTROMAGNETICS}

Copyright (C) 2013 by National Taiwan University Press and World Scientific Publishing Co. Pte. Ltd.

All rights reserved. This book, or parts thereof, may not be reproduced in any form or by any means, electronic or mechanical, including photocopying, recording or any information storage and retrieval system now known or to be invented, without written permission from the Publisher.

For photocopying of material in this volume, please pay a copying fee through the Copyright Clearance Center, Inc., 222 Rosewood Drive, Danvers, MA 01923, USA. In this case permission to photocopy is not required from the publisher.

ISBN 978-981-4412-17-9

Printed in Singapore 


\section{To my wife June and our children \\ Maggie, Kathy, Kenny and George}


This page intentionally left blank 


\section{Preface}

This book is the outgrowth of the lecture notes I developed while teaching at National Taiwan University as a visiting professor during the period of December 2006 to February 2007. Five Special topics in Electromagnetics are covered in this book which can be taught as a graduate course in Electromagnetics. The prerequisite to understand this book is some experience in undergraduate courses on this subject. The format of this book is somewhat unusual because the material is presented with detailed mathematical derivation, with an intention for self-taught students and researchers to read this book. The special topics covered in this book are becoming more popular in research areas of interaction of Electromagnetic field with material bodies, the practical applications of Electromagnetic wave in biomedical engineering, and the radar target identification.

Chapter 1 presents a set of modified Maxwell's equations with magnetic sources and the application of these equations in solving problems in heterogeneous multiple media. The Equivalence Principle is mathematically derived and its application to the interaction of an EM wave with a dielectic body is discussed.

Chapter 2 derives Vector Wave Functions and demonstrates their applications to the problems involving the interaction of EM waves with material bodies in various environments. The result of an analysis gives the answer to the question of why the sky looks blue.

Chapter 3 deals with Dyadic Green's functions and their applications. The convergences problem of Dyadic Green's functions when applied in some source regions or conducting regions is discussed in details. The principal value integration and the correction term are derived. These mathematical problems are explained with physical pictures to facilitate the understanding of Dyadic Green's functions. 
Chapter 4 presents a practical application of EM waves in biomedical area of microwave lifedetection system. The scheme of detecting a very small movement of biological body with EM waves is studied.

Chapter 5 presents a new method of the radar target identification with EM pulse and the scheme of the Extinction-pulse method.

The author is indebted to the College of Electrical Engineering and Computer Science, National Taiwan University, the author's Alma Mater, for their assistance. Thanks are expressed to Ms. Wening Chao, Mr. Yung-Chih Tsai, Mr. Yu-Che Lin, Mr. Jing-De Huang, Mr. Guo-Cyuan Guo and Ms. Hui-Jun Lian for typing the first draft of this book. The hospitality rendered by Prof. Ruei-Beei Wu during my stay at National Taiwan University is appreciated. Furthermore, my sincere gratitude is expressed to Prof. Huei Wang, my former student now a famous professor himself, for his many helps in arranging my visit to Taiwan and the preparation of this book. Without his help this book will not be possible.

I should not forget to acknowledge the contribution made by many of my former students and Prof. Dennis P. Nyquist and Prof. Edward J. Rothwell of Michigan State University, East Lansing, Michigan, where I taught for about forty years. Many results presented in this book were produced by them under my supervision.

Kun-Mu Chen San Diego, California. 2007 


\section{CONTENTS}

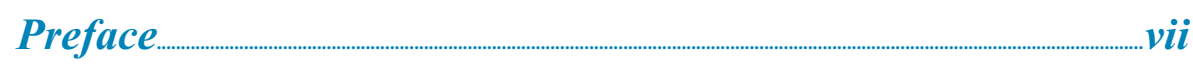

Chapter 1. General Maxwell's Equations and Solutions................... 1

1.a Modified Maxwell's Equations with Magnetic Source Terms.................. 1

1.b General Solutions of Maxwell's Equations in Heterogeneous

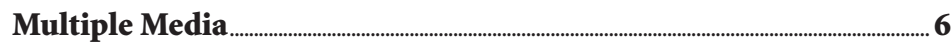

1.c Mathematical Derivation of Equivalence Principle ...................................... 28

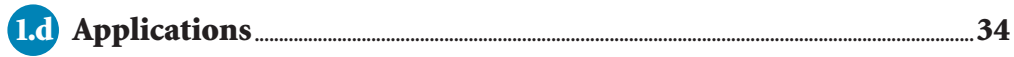

Chapter 2. Vector Wave Functions and Applications..._... 39

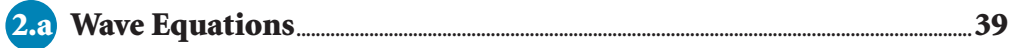

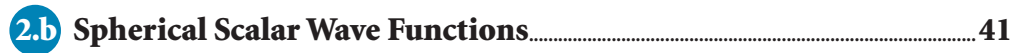

2.c Spherical Vector Wave Functions …………...................................................... 46

2.d Scattering of a Conducting Sphere — Application .....................................54

2.e Interaction of a Material Body with EM field in a Rectangular

Cavity. .72 
3.a Dyadic Analysis.

3.b Dyadic Green's Function.

3.c Dyadic Green's Function in Source Region or

Conducting Medium

3.d Applications of Dyadic Green's Function. 105

3.e Physical picture of Dyadic Green's Function in Source Region..... 109

Chapter 4. Biomedical Application of Electromagnetic Waves....117

4.a Microwave Life-Detection Systems 118

4.b R.F. Life-Detection Systems for Searching Human Subjects under Earthquake Rubble or Behind Barrier. 133

4.c Analysis of Interaction Between ELF-LF Electric Fields and Human Bodies. 153

Chapter 5. Radar Target Identification with Extinction-pulse (E-pulse) Method

5.a Radar Target Identification by E-pulse Method — Time-Domain Analysis 178

5.b E-pulse Method — Frequency Domain Analysis 195

5.c Application of E-pulse Technique to

Early-Time Target Response 205 